\title{
Lead Tip Device
}

National Cancer Institute

\section{Source}

National Cancer Institute. Lead Tip Device. NCI Thesaurus. Code C50326.

A device designed to form the end of an electrical lead. 